\title{
Sistem Pengaturan Penggunaan Perangkat Listrik Rumah Tangga Menggunakan Komputer Mini Hemat Daya
}

\author{
Hironimus Leong \\ Program Studi Teknik Informatika, \\ Universitas Katolik Soegijapranata \\ email: marlon.leong@unika.ac.id \\ Suyanto E.A \\ Program Studi Teknik Informatika, \\ Universitas Katolik Soegijapranata \\ email: seantonius@unika.ac.id
}

\begin{abstract}
The use of household electrical appliances can be controlled automatically by utilizing computer that can control when the device is switched on or off according to the schedules and conditions provided by the user.

Provisions and schedules can be determined by the user through software management that regulates the date and time regularly or specifically.

By utilixing "Rasberry Pi" energy saving mini computer that that is equipped with special software, electrical control center can be connected to the mini computer and the user can use integrated software to control the use of household electrical appliances according to the need on determined schedules.

The final goal of this research is to produce computer based system to manage the electric use that results in the efficiency of the use of electricity in the household and to create smart house that environmentally friendly
\end{abstract}

Keywords: electrical devices, management, setting, rasberry pi, saving power

\begin{abstract}
Abstrak
Penggunaan perangkat listrik rumah tangga dapat dikendalikan secara automatis dengan memanfaatkan kemampuan komputer yang mampu mengontrol kapan perangkat tersebut dinyalakan atau dimatikan sesuai dengan jadwal dan ketentuan yang diberikan oleh pengguna.

Ketentuan dan jadwal dapat ditentukan oleh pengguna melalui software manajemen yang mengatur waktu tanggal dan jam baik secara regular maupun jadwal dan jam yang berlaku secara khusus atau spesifik.

Dengan memanfaatkan komputer mini hemat "Raspberry Pi” dan dilengkapi dengan software khusus, maka pusat kontrol listrik dapat dihubungkan ke komputer mini tersebut dan pengguna dapat memanfaatkan software terintegrasi untuk mengatur penggunaan perangkat listrik rumah tangga sesuai dengan kebutuhan pada jadwal-jadwal yang sudah ditentukan.

Tujuan akhir dari penelitian ini adalah menghasilkan sistem berbasis komputer untuk mengatur penggunaan listrik yang berdampak pada efisiensi penggunaan listrik dalam rumah tangga serta menciptakan rumah pintar yang ramah lingkungan.
\end{abstract}

Kata kunci: perangkat listrik, manajemen, pengaturan, raspberry pi, hemat daya 


\section{PENDAHULUAN}

Perkembangan komputer dalam bidang komputasi semakin kecil dan semakin hemat daya, umumnya disebut sebagai mini komputer dengan spesifikasi yang cocok dalam bidang penelitian dan pendidikan.

Salah satu produk dari komputer mini yang tersedia adalah Raspberry Pi, komputer berukuran kecil dengan penggunaan daya yang sangat kecil dan sudah tersedia dengan sistem operasi dan software di dalamnya.

Salah satu kemampuan dari Raspberry Pi adalah adalah kemampuannya terhubung dan berinteraksi dengan perangkat elektronik lainnya. Salah satu kemampuan yang dimiliki adalah mengendalikan perangkat listrik untuk ON dan OFF untuk menyalakan dan mematikan perangkat listrik dengan kendali software.

Dengan menggunakan software bantu maka kendali perangkat listrik dapat dialihkan dari peran manusia ke komputer. Sistem ini berlaku khusus untuk perangkat listrik yang dikendalikan secara terjadwal.

Untuk mencapai tujuan perangkat listrik yang dinyalakan atau dimatikan secara terjadwal, maka dibutuhkan software yang dibangun khusus untuk merekam jadwal dan perangkat yang terhubung dengan Raspberry Pi.
Software berfungsi sebagai manajer yang dapat mengatur semua perangkat tersambung, menjadwalkan baik hari maupun jam perangkat dinyalakan atau dimatikan serta dapat berinteraksi langsung dirinya sendiri dengan perangkat lain yang terhubung.

Dengan membangun sistem terintegrasi antara komputer mini Raspberrry Pi dan software manajer di dalamnya, maka dapat menghasilkan sistem yang dapat diterapkan untuk mengendalikan perangkat lain untuk dinyalakan maupun dimatikan pada jadwal tertentu yang sudah ditentukan.

\section{LANDASAN TEORI}

1. Komputer mini Raspberry Pi

Produk Raspberry Pi lahir dari penelitian yang dilakukan di laboratorium komputer Universitas Cambridge pada tahun 2006; dengan tujuan untuk menciptakan komputer minim di bidang pendidikan dan penelitian. Untuk kepentingan tersebut, maka bentuk Raspberry Pi dibuat dengan ukuran $85.60 \mathrm{~mm}$ x 53.98mm x $17 \mathrm{~mm}$ dan berat sekitar 45 gram.

Oleh karena sifatnya sebagai perangkat komputer, maka Raspberry $\mathrm{Pi}$ juga dilengkapi dengan sistem operasi, aplikasi lengkap dan juga kemampuan untuk menuliskan kode program. 
Karena tujuan dari pembuatan Raspberry Pi adalah bidang penelitian, maka perangkat dilengkapi dengan 17 GPIO (General Purpose Input Output) dengan tegangan 3,3 Volt. GPIO dapat digunakan untuk menghubungkan perangkat Raspberry $\mathrm{Pi}$ dengan perangkat lain dengan memanfaatkan kabel data dan rangkaian elektronika

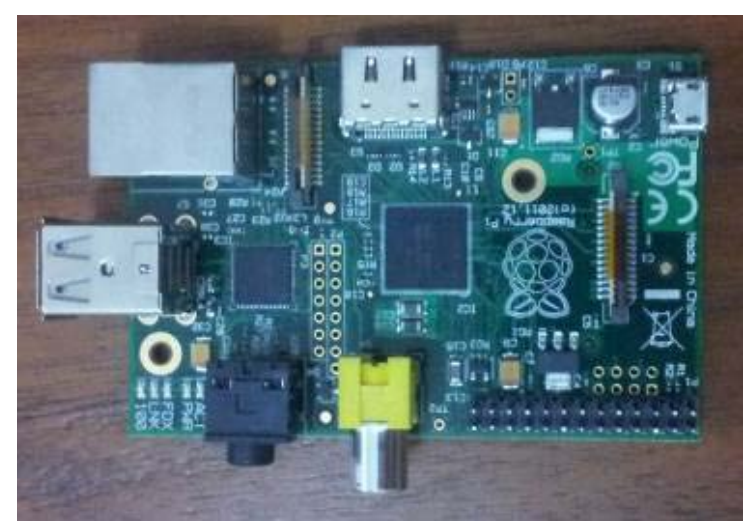

Gambar 1

Komputer Mini Raspberry Pi

\section{Software bahasa pemrograman}

Untuk memudah mengembangkan program atau aplikasi dalam perangkat Raspberry Pi, maka dilengkapi dengan bahasa pemrograman lengkap. Bahasa pemrograman yang standar dan ada dalam perangkat Raspberry $\mathrm{Pi}$ adalah bahasa pemrograman Python dan bahasa Pemrograman Gambas. Kedua bahasa pemrograman dapat membaca semua komponen Raspberry Pi termasuk GPIO yang terhubung dengan perangkat lain.
Selain kedua bahasa pemrograman dasar tersebut, Raspberry Pi dilengkapi juga dengan software basis data yang secara khusus digunakan untuk mengolah data mentah menjadi informasi yang berguna bagi pengguna perangkat.

Dengan demikian, perangkat Raspberry dapat mentransformasikan inputan menjadi output. Data perangkat elektrik yang terhubung dengan Rasberry Pi, dapat dicatat jenis perangkat, jadwal dan juga kondisi alat harus bernilai ON atau OFF yang sudah tersimpan dalam basis data. Output dari proses tersebut adalah kendali perangkat berdasarkan nilai hasil olahan dari data yang tersimpan.

\section{METODE PENELITIAN}

Dalam mengembangkan sistem ini, terdapat sejumlah langkah yang dilakukan melalui 6 tahapan.

Tahap Persiapan: yaitu mempersiapkan bahan dasar seperti komputer mini Raspberry Pi, software bantu yang akan digunakan yaitu Python dan Gambas. Tahapan persiapan mempelajari bagaimana struktur Raspberry Pi dan GPIO bekerja serta semua perangkat lunak yang dapat dimanfaatkan secara maksimal dalam pengembangan sistem. 
Tahap Survey: Tahapan ini melihat secara langsung berbagai peralatan listrik yang digunakan baik di kantor maupun di rumah, waktu penggunaan dan berbagai syarat kondisi peralatan tersebut digunakan.

Tahap Desain Sistem: Tahapan dimana permasalahan kontrol peralatan listrik oleh Raspberry Pi dirancang dalam bentuk bangunan sistem secara utuh baik basis data, kendali sistem, bahasa pemrograman dan juga desain perangkat Raspberry Pi agar dapat bekerja secara terintegrasi.

Tahap Pengembangan Sistem: adalah implementasi dari desain sistem yang sudah dirancang, meliputi: perakitan perangkat menjadi satu kesatuan, penulisan kode program dan integrasi sistem secara keseluruhan agar dapat bekerja sama dengan sempurna.

Tahap Uji Coba: tahapan untuk mencoba secara langsung sistem yang sudah jadi apakah dapat mengendalikan peralatan listrik sesuai dengan yang diharapkan.

\section{HASIL}

Hasil rancangan sistem tertuang dalam bentuk implementasi rangkaian sistem seperti gambar 2 di bawah ini.

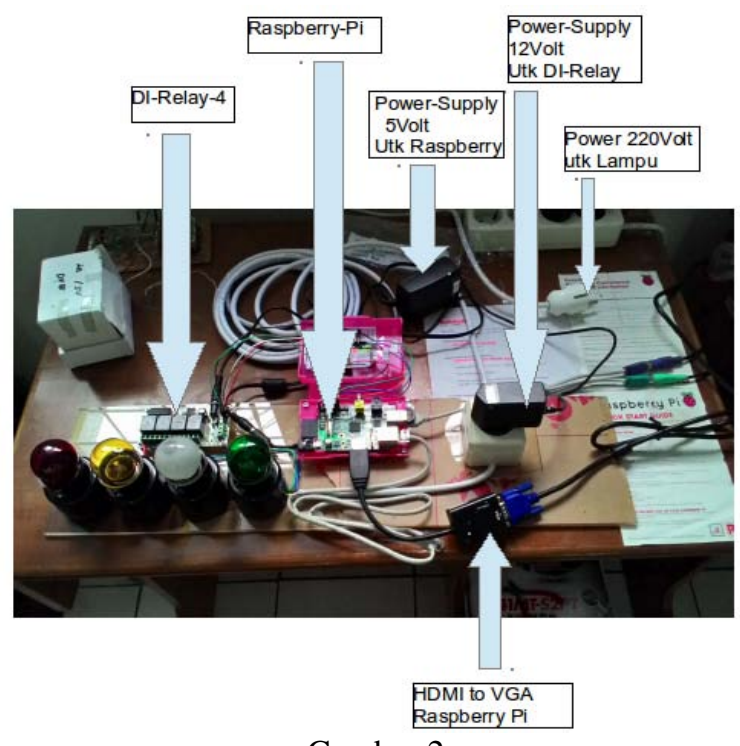

Gambar 2

Implementasi Sistem

Oleh karena sistem menggunakan sambungan perangkat listrik dengan perangkat Relay 220 Volt, maka perlu dihubungkan dengan perangkat Raspberry Pi. Gambar 3 adalah perangkat relay yang digunakan.

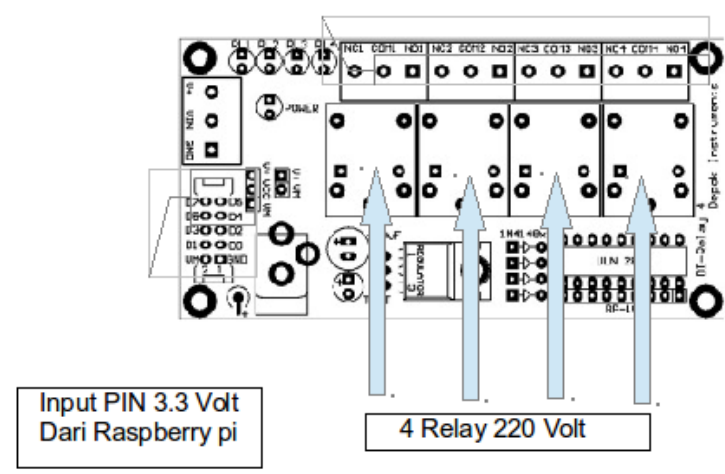

Gambar 3

Perangkat Relay 220 Volt

Sedangkan gambar 4 adalah implementasi keseluruhan dari sistem perangkat Raspberry Pi dengan relay yang digunakan. 


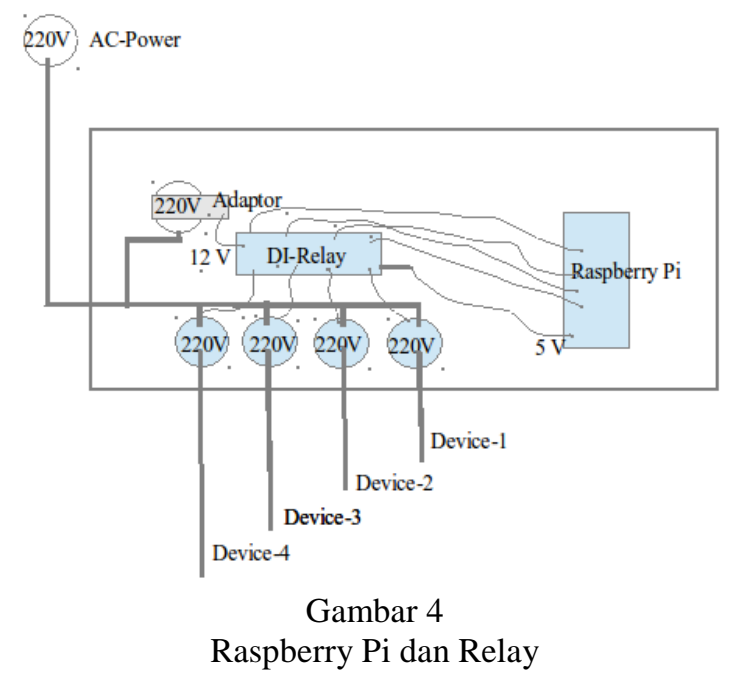

Dengan implementasi sistem yang perangkat Raspberry yang sudah jadi, maka terdapat 4 stop kontak listrik yang akan dikendalikan, dan bisa ditambahkan lebih banyak. Setiap perangkat memiliki identitas nama perangkat sehingga memudahkan pengembangan software untuk mengontrolnya.

Oleh karena pencatatan jadwal bagi setiap perangkat adalah wajib sehingga dapat dikendalikan, maka harus dicatat jadwal hari dan tanggal tertentu perangkat tersebut dalam posisi nyala atau mati (ON OFF).

Dalam software, berikut adalah implementasinya dalam bahasa pemrograman Gambas.

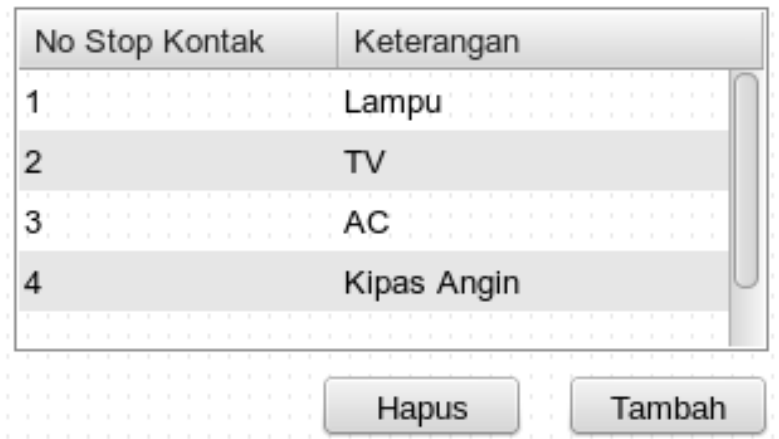

Gambar 5

Daftar Perangkat Listrik

Untuk mencatat jadwal (ON-OFF) dari perangkat yang dimaksud, maka perlu dibuatkan tampilan program untuk pencatatan jadwal perangkat yang dinyalakan secara berkala dengan jadwal yang sudah pasti. Berikut adalah implementasinya.

Tanggal 13 Mei 2015
Mulai Jam $17: 00$ SD 21:00
Stop Kontak
4. Kipas Angin
Pengaturan Jadwal Perangkat Reguler
Sedangkan untuk mengontrol jadwal
perangkat pada waktu tertentu saja, dapat
diprogram sebagai berikut:




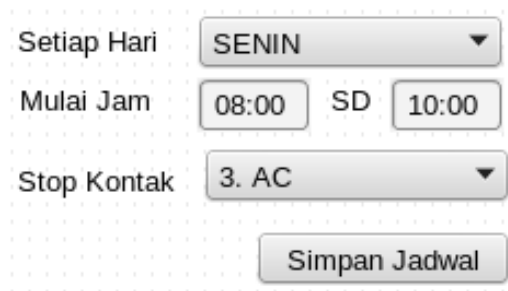

Gambar 7

Pengaturan Jadwal Khusus

Dengan demikian, maka proses integrasi sistem dengan jadwal reguler dan jadwal tertentu pada perangkat listrik dapat dikontrol melalui software.

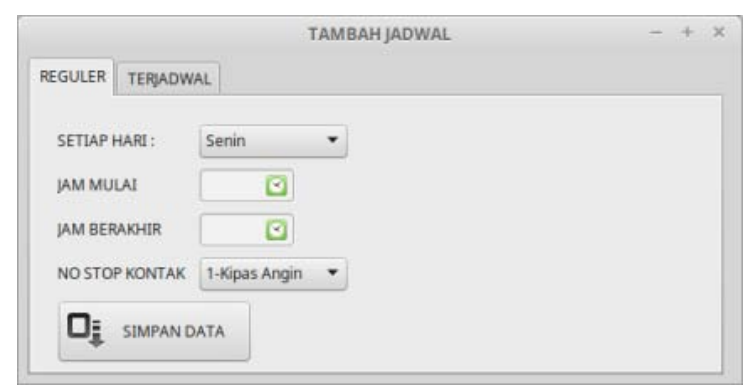

Gambar 8

Pengaturan Jadwal Reguler dan Terjadwal Perangkat Listrik

\section{Implementasi sistem secara}

keseluruhan dapat terintegrasi antara perangkat Raspberry Pi dan juga software manager. Sistem tersaji seperti pada gambar 9.

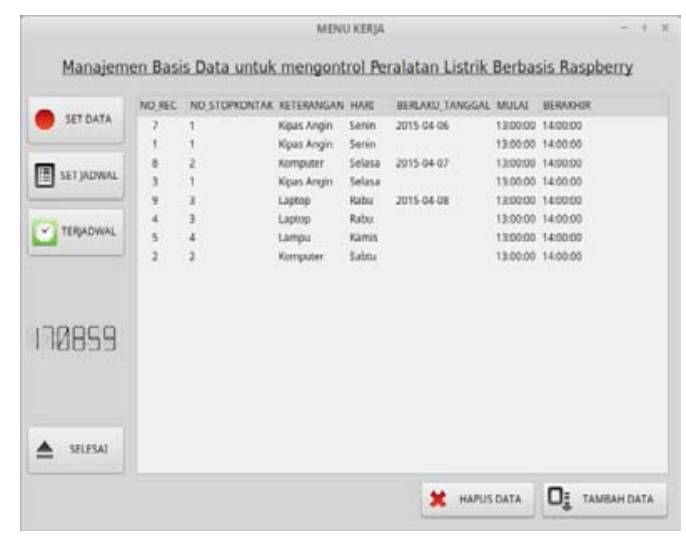

Gambar 9

Sistem Kontrol Terintegrasi
Dari hasil sistem yang sudah jadi, maka dilakukan uji coba sistem secara keseluruhan untuk diamati apakah sistem berjalan dengan baik tanpa kendala.

Langkah awal adalah mengidentifikasi setiap perangkat listrik yang terhubung ke perangkat Raspberry Pi.

Tabel 1

Daftar Perangkat Listrik

\begin{tabular}{l|l} 
Nomor Kontak & \multicolumn{1}{|c}{ Keterangan } \\
\hline 1 & Kipas Angin \\
2 & Komputer \\
3 & Laptop \\
4 & Lampu
\end{tabular}

Kemudian diatur secara terjadwal sebagai berikut:

Tabel 2

Penjadwalan Perangkat Listrik

\begin{tabular}{l|ccl} 
Hari & Mulai & Selesai & Keterangan \\
\hline Senin & $13: 00: 00$ & $14: 00: 00$ & Kipas Angin \\
Selasa & $13: 00: 00$ & $14: 00: 00$ & Komputer \\
Rabu & $13: 00: 00$ & $14: 00: 00$ & Laptop \\
Senin & $13: 00: 00$ & $14: 00: 00$ & Kipas Angin \\
Sabtu & $13: 00: 00$ & $14: 00: 00$ & Komputer \\
& & & \\
Selasa & $13: 00: 00$ & $14: 00: 00$ & Kipas Angin \\
Rabu & $13: 00: 00$ & $14: 00: 00$ & Laptop \\
Kamis & $13: 00: 00$ & $14: 00: 00$ & Lampu
\end{tabular}

Hasil uji coba keseluruhan untuk memastikan bahwa sistem bekerja dengan baik disajikan dalam bentuk tabel 3 . 
Tabel 3

Hasil Uji Coba Sistem

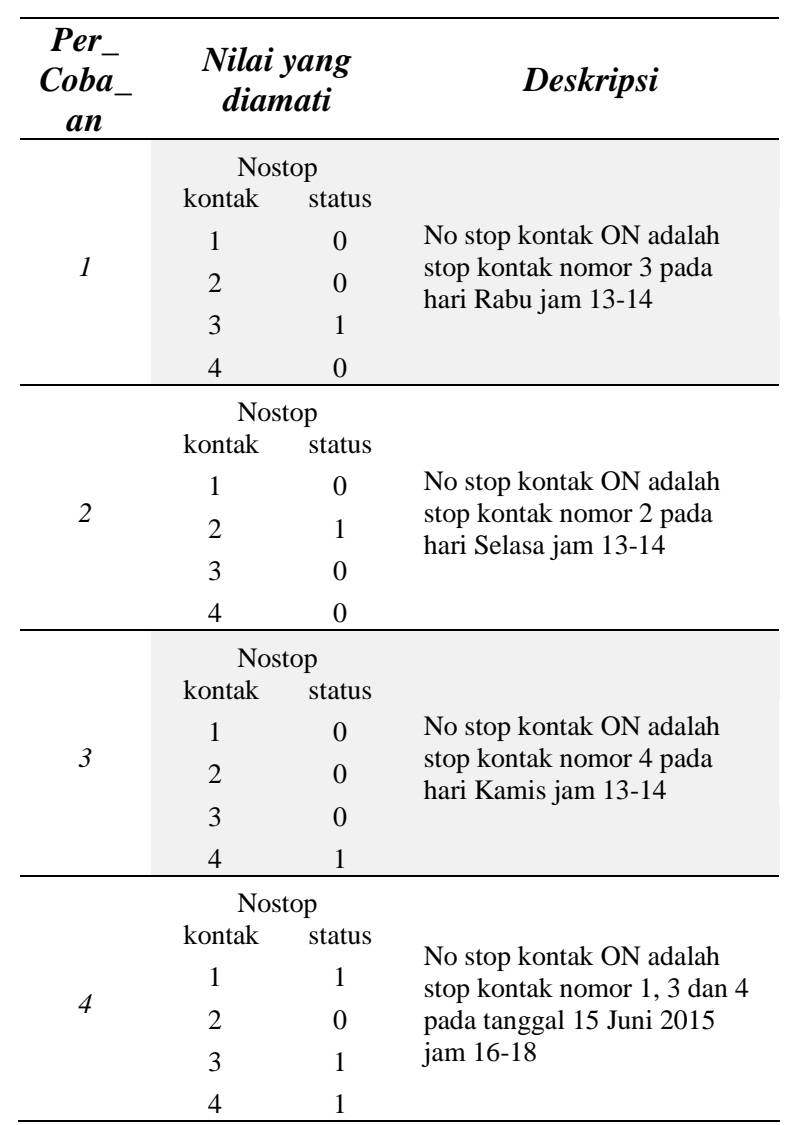

\section{SIMPULAN}

Pengembangan sistem untuk mengontrol penggunaan perangkat listrik secara terjadwal dapat dilakukan dengan memanfaatkan komputer mini hemat daya Raspberry Pi.

\footnotetext{
Sistem yang dikembangkan memanfaatkan kemampuan perangkat Rasberry Pi dan ditunjang dengan software bantu yang mampu menjadi manajer dalam mengendalikan perangkat dengan posisi nyala atau mati (ON-OFF) sesuai dengan jadwal yang ditentukan oleh pengguna sistem.
}

Penelitian ini masih terjadwal dalam bentuk hari/tanggal dan waktu yang dikontrol secara komputerisasi. Dalam implementasi Raspberry Pi, dimungkinkan dengan pengendalian perangkat berdasarkan sistem sensor seperti sensor kamera maupun sensor cahaya yang diintegrasikan sebagai perangkat tambahan lainnya

\section{DAFTAR PUSTAKA}

Wolfram Donat. (2014). Learn Raspberry Pi Programming with Python

Jay A Kreibich. (2010) Using SQLite

Kenneth C Laudon. (1996). Management Information System

Peter Membrey. (2013). Learn Raspberry Pi with Linux.

Raymond MCLeod (1998). Sistem Informasi Manajemen 